\title{
Análise, Musicologia, Positivismo
}

\author{
Regis Duprat
}

Permeia na incipiente musicologia brasileira uma tendência, que se pretende recente, de depreciar a crítica e abordagem impressionista-literário-retórica da obra musical tanto quanto a transcrição-restauração, dissociando esta última, equivocadamente, de toda atitude analítica prévia, concomitante e ou posterior, como se uma transcrição não resultasse de uma postura teóricoanalítico-histórica integrada e permanente. Ao mesmo tempo, supervaloriza-se a "análise musical" como panacéia universal das doenças da musicologia, ou da própriamúsica.

Dizemos que essa tendência "se pretende recente" porque, na verdade, ela conheceu diversos fluxos no passado da nossa musicologia. Diríamos que datam da década de 1920 os primeiros ensaios dessa depreciação, com os escritos de Mário de Andrade e, na década seguinte, os de Luís Heitor; na de 40 as pesquisas e descobertas de Curt Lange; na de 50, ainda Luís Heitor, Oneyda Alvarenga, na músicapopular brasileira; na de 1960, o saudoso padre Jaime Dinis, Gérard Béhague, José Maria Neves e nós mesmos, dentre outros, integrados no repúdio à crítica retórica da obra musical e à leviandade das citações infundadas.

\footnotetext{
* O presente trabalho constituiu comunicação no V Encontro Nacional da ANPPOM - Associação Nacional de Pesquisa e Pós-graduação em Música, em Salvador, Bahia, em setembro de 1992.
} 
A tendência recente de que falamos reflete diretamente a ocupação quantificada do meio acadêmico por parte de segmentos ponderáveis da comunidade musical, ou seja, a presença da música na Universidade brasileira e a expansão da qualificação profissional e da titulação. Nesse esquema de ocupação, tem um espaço razoável uma geração de especialistas titulados especialmente nos Estados Unidos e que desse país trazem uma formação e uma preocupação voltadas primordialmente para a análise musical.

Nos. Estados Unidos, onde a expansão da musicologia na Universidade tem seu início significativo na décadade 1930, aquele país conheceu um incremento indiscutível na área, no período da Segunda Grande Guerra, com a imigração de musicólogos refugiados, sobretudo anglo-saxões. A ascenção da musicologia e da análise na década de 1950 ocorreu ali, na Universidade.

No Brasil, não obstante a presença da música na Universidade ser anterior ao início da década de 1970, os estudos pós-graduados irão gerar uma substancial contribuição do setor para a musicologia, tanto na UFRJ como na USP, disseminados, em seguida, em sintonia com a legislação oficial, por grande número de universidades do país. A ANPPOM, que constitui forma superior de organização e de incentivo à pesquisa, surge somente no final da década de 1980.

Não quero repetir aqui o eficiente panorama dessa movimentação traçado, no que se refere aos Estados Unidos, por J. Kerman em seu livro Musicologia (trad. Álvaro Cabral, São Paulo, Martins Fontes, 1987), que sistematicamente será invocado neste trabalho, nas suas abordagens, conceitos e conclusões. Além da produção, desde a década de 1940, daqueles imigrados como Schoenberg, Reti e outros, temos a considerar a produção em língua inglesa e $o$ movimento editorial envolvendo traduções para o inglês, especialmente do alemão, no pós-guerra. Podemos falar, assim, de uma musicologia anglo-saxônica consumida nos Estados Unidos no período de 1940-1960, da qual pelo menos quase 30 trabalhos integrados na bibliografia do artigo Análise, de Ian Bent (Grove 
VI), foram publicados naquele país dentre os 106 títulos selecionados, ou seja, quase $30 \%$ do total.

E já que citamos o artigo de Bent, abordemos a sua bibliografia composta de cerca de 530 trabalhos, de um período que vai de 1563 a 1977 (414 anos).

\begin{tabular}{|lccc|}
\hline Período & Itens & Com a palavra "análise" & Percentagem \\
\hline $1500-1851$ & 27 & 0 & $0 \%$ \\
$1852-1900$ & 38 & 5 & $13 \%$ \\
$1901-1930$ & 89 & 13 & $15 \%$ \\
$1931-1940$ & 31 & 5 & $16 \%$ \\
$1941-1950$ & 23 & 4 & $17 \%$ \\
$1951-1960$ & 84 & 18 & $21 \%$ \\
$1961-1970$ & 226 & 80 & $35 \%$ \\
$1971-1977$ & 109 & 36 & $33 \%$ \\
Totais & 627 & 161 & $25,5 \%$ \\
\hline
\end{tabular}

Nos títulos desta relação, cuja eficácia e reconhecimento da comunidade musicológica internacional se dispensa comprovar, a palavra análise surge em 1852 para se repetir em 1885, 87, 1890, 1893 e 1901, retornando, então, com regularidade relativa em 1910 e, somente a partir de 1925, com regularidade constante. Os anos de guerra, tanto da primeira como da segunda, são de quase total esterilidade. E nessa relação da presença da expressão análise no título dos trabalhos, podemos destacar a década de $1960 \mathrm{com}$ a maior incidência com 80 itens, ou seja, $35 \%$ do total arrolado por Ian Bent para a década. Já na década de 1970 aqueles números caem para 36 itens, mantendo $33 \%$ do total da década, porém, quase $3 / 4$ desses títulos estão concentrados nos três primeiros anos dessa década. Não obstante $o$ arrolamento atingir até apenas $o$ ano de 1977, uma atualização da bibliografia não chegaria jamais a dobrar (incluindo-se os anos de 1978 a 1980) o total de publicações incluídas na bibliografia de análise para igualar o total da década de 1960, que é de 226 títulos. A distribuição dessa listagem por década poderia ser desprezada alargando o de 1960 até o ano 
de 1973, pois no período imediatamente subseqüente é evidente a queda da freqüência da palavra análise nas publicações.

Vê-se, portanto, que não só diminuiu o número de publicações sobre análise, como também a própria expressão povoou decrescentemente os títulos dos trabalhos selecionados na referida bibliografia. Completemos a listagem bibliográfica de Bent com o artigo de J.J.Nattiez, "Semiologia Musical e Pedagogia da Análise" (Revista Opus 2, da ANPPOM, junho 1990, p. 50-58). Nesse trabalho, Nattiez atenta para o fato de que "entramos numa fase da história da análise musical que nos obriga a admitir a coexistência dos diferentes modelos [de análise] disponíveis". E cita cinco obras surgidas entre 1985 e 1988 que registram, todas, a pluralidade dos paradigmas disponíveis:

Kerman : 1985, o capítulo "Análise, Teoria e Música Nova”, in Musicologia;

Marc Devoto: 1986, o artigo "Análise", do novo Harvard Dictionnary of Music;

Ian Bent: 1987 (1980), o artigo "Análise", do Grove VI;

N.Cook: 1987, "A Guide to Musical Analysis";

J.Dunsby e Whittal: 1988, "Music Analysis in Theory and Practice".

Com base nessas cinco obras, Nattiez estabelece uma lista de dez tendências da análise musical no nosso século, que convém sumarizar, por subliminaridade, aqui:

1. A Harmonia tonal, de Schenker;

2. Harmonia, forma e motivo, cf. Schoenberg;

3. Análise motívica e temática, de Reti;

4. Set-Theory, de Forte;

5. Análise rítmica e melódica, de Meyer;

6. Musical criticism, de Kerman, Rosen, Treitler;

7. Semiologia musical, de Ruwet e Nattiez;

8. Análise por computador;

9. Teoria generativa, de Lerdahl e Jackendorff;

10. Músicas de tradição oral. 
Essa é uma relação extremamente selecionada, que dispensa qualquer esforço de quantificação, ou de complementação da listagem bibliográfica de Bent. É aqui que ensaiamos as primeiras conclusões sobre as observações quantificadas do início desta comunicação. Quero referir-me à natureza daqueles cinco trabalhos citados por Nattiez, o primeiro dos quais, de 1980, é justamente o de Bent. Os cinco trabalhos são de natureza retrospectiva e não propositiva, isto é, nenhum deles propõe um modelo novo ou inovador de análise. Todos eles abandonam qualquer resquício do que Kerman dizia em seu livro referindo-se à teoria musical, de uma situação acadêmica vivida no passado e caracterizada por "ortodoxias opressivas". Essa natureza é um verdadeiro libelo contra as tendências analíticas e a assimilação delas, especialmente as monistas fundamentadas num princípio único, exclusivo e dogmático de análise. E libelo contra qualquer pretensão positivista de se compreender, interpretar e explicar a obra musical com base exclusiva na decifração ou percepção de sua eventual estrutura, seja ela qual for, pois será sempre parametrizada. E não importa quantos parâmetros sejam usados, pois não é o somatório deles que superará a essência decifratória de cada um deles isoladamente. Como lembra Vattimo (G. Vattimo, Etica dell'Interpretazione, Turim, Rosemberg \& Sellier, 1989, p. 108), a psicanálise lacaniana já superara, a "psico-análise" como mero instrumento de desvelamento e reintegração da transparência, ou seja, como subjacência que se trataria de fazer aflorar. A análise não conseguiu, até hoje, alcançar a conscientização dessa impotência inerente ao próprio processo do conhecimento, desguarnecendo-se gnosiológica, epistemológica e ontologicamente.

Ouçamos ainda uma vez Kerman (p.94):

"Embora a musicologia e a análise possam ver vistas como contraditórias e atécomo abordagens rivais de música, ambas foram planejadas para prosperar na atmosfera intelectual do neopositivismo. O atrativo da análise sistemática era propiciar uma visão positivista da arte, uma crítica que poderia 
apoiar-se em operações precisamente definidas e aparentemente objetivas, e repelir os critérios subjetivos".

E acrescenta que esse esquema se aplica a toda a análise tematicista, à schenkeriana, ao sistema analítico de base psicológica de Meyer, à análise teórica de conjunto, de Forte e à análise semiológica de Ruwet e Nattiez. Pouco sobrou da análise nessa pecha de positivismo [da análise].

Mas em que consistiria realmente, para Kerman, o positivismo da análise? Para que serviria a análise? (p.88). Serviria para conhecer o que ocorre com a partitura? para ver se concorda com a teoria? A verdadeira análise seria feita em apoio à crítica? Seriam exercícios analíticos em apoio à teoria? É o que comenta Kerman à p. 93 :

"Como a dos musicólogos é a superficialidade, a deficiência dos analistas é a miopia. A concentração obstinada [deles] nas relações internas numa única obra de arte é, em última instância, subversiva, quanto a qualquer visão razoavelmente completa da música. A estrutura autônoma da música é apenas um dos muitos elementos que contribuem para seu significado e importância. A preocupação com a estrutura é acompanhada da negligência em outros aspectos vitais - não só todo o complexo histórico referido mas também tudo que torna a música afetiva, tocante, emotiva e expressiva. Ao retirar-se a partitura de seu contexto a fim de examiná-la como organismo autônomo, o analista retira esse organismo da ecologia que o sustenta".

Um aspecto que não é destacado em nenhum momento por Kerman é a consideração da análise como tendência estruturalista ou neo-estruturalista no presente, ou seja, que parte do pressuposto de uma estrutura já existente, previamente depositada na obra e descoberta pelo analista, explicando o conjunto dos significados altamente formalistas de uma obra; da pretensa posição neutra do 
observador e do estruturalismo como "restauração positivista" (G. Vattimo, id, ib., p.40 e seg., que logo passamos a glosar ).

Eis que a voga do estruturalismo como Koiné (consenso) do pensamento ocidental predomina justamente no período de prestígio indiscutível da palavra análise na musicologia ocidental, ou seja, os anos 60-70. O Brasil periférico estaria, assim, adentrando tardiamente, de forma ultrapassada, a fase do prestígio da análise musical, num momento em que os centros do sistema cultural ocidental passam, como vimos, em termos de análise, a prognosticar, no dizer de Nattiez, uma "coexistência dos modelos disponíveis", numa quebra dos sistemas monistas, auto-suficientes, radicais e formalistas, que constituem, inclusive, uma retomada caduca dos princípios neopositivistas e neo-estruturalistas, que incluem as diversas tendências desconstrutivistas, geracionistas e transformacionistas, numa resistência inconsciente à penetração definitiva e inapelável da nova hermenêutica.

Erigindo com prioridade a pretensa neutralidade do observador, o método estruturalista conduziu à repressão dos conteúdos, os quais perdem importância quando a preocupação do sujeito usuário do método se estabelece como exclusivamente cognitiva. Como destaca Gianni Vattimo, é justamente sobre a pureza e cognitividade desse interesse do sujeito que se trata de interrogar.

A crise do estruturalismo se esboçou com a emersão das culturas não ocidentais no concerto mundial, o que não deixa de constituir uma grande ironia para uma tendência que se configurou exatamente na base de estudos sobre o mito levados a efeito pelo fundador do estruturalismo, Lévy-Strauss. Desde então, o problema entre observador e observado já não podia ser reprimido ou ignorado. É claro que nesse contexto novo as etnomusicologias se destacam, com nítida vantagem de lucidez, dentre as atividades musicológicas tradicionais e da própria análise; falamos em questão de método pois a abordagem e o diálogo com as outras culturas não podia erigir-se em bases puramente descritivas do objeto.

Relegando a segundo plano a essencialidade dos conteúdos e a própria historicidade (é o que ocorre com as análises às quais o 
próprio Kerman atribui o preocuparem-se exclusivamente com a obra analisada, resistindo a abordá-la no contexto histórico, seja estilístico ou biográfico), o estruturalismo se desgasta, dando passagem inevitável, nos anos 80, à koiné cultural hermenêutica, legitimada pela interpretação, única capaz de retomar, na formulação gadameriana, a chamada Wirkungsgeschichte, a História de eventos, que sustenta a interpretação (de textos, é claro) não como uma mera descrição por parte de um observador neutro, mas como evento dialógico de onde os interlocutores em jogo (observador e obra) saem modificados.

Como acentua Vattimo, o pensamento estruturalista tem como telos, norma, fio condutor, a projeção pela consciência observadora, de ordens articuladas segundo regras. É o caso da análise nas suas vinculações, até projeções, com a teoria musical, já que ela não seria senão, em última instância, a identificação e o desvelamento sistemáticos de princípios já previstos naquela, ou mesmo transgressões dela... e aplicados na construção original da obra analisável. Já o pensamento hermenêutico enfatiza justamente observador e observado, que pertenceriam ambos a um mesmo horizonte comum, concebendo a verdade como evento que modifica esse horizonte com base no diálogo; e a interpretação da obra é um diálogo entre interlocutores.

É nesse sentido que a hermenêutica retoma a crítica existencialista ao racionalismo metafísico hegeliano e ao cientificismo positivista, que indiscutivelmente constituiu um formante do estruturalismo. Contra a pretensa neutralidade estruturalizante e neopositivista do analista, a hermenêutica prognostica a integração do sujeito observador no jogo da compreensão e no evento da verdade da obra. E mais, na perspectiva gadameriana, enseja a experiência extrametódica.

Não é absolutamente a nossa intenção desmotivar os jovens na prática da análise. Pelo contrário, eu mesmo, em todo o decorrer da minha trajetória, jamais deixei de praticá-la e tudo que publiquei no passado depõe a corroborar essa afirmação. Porém, não posso deixar de advertir sobre a fragilidade da episteme analítica, 
sobretudo no que tange à sua tendência fortemente exclusivista, estruturalista e neopositivista, que pretende vislumbrar, na decifração de uma configuração estrutural subjacente previamente contida na obra, os mecanismos suficientes de apreensão, comprensão e explicação da obra musical.

Para a analítica existencial heideggeriana o modo de ser do homem no mundo se caracteriza pela precompreensão (VorverstŠndnis). Ele desde sempre já compreende o mundo e nele se compreende. Esta é uma estrutura existencial que é um modo de ser e nele há unidade total entre intuição e entendimento, onde inteligibilidade e sensibilidade não se podem separar. Aí, a racionalidade não ocorre senão nos limites da sua condição histórica. Portanto, a racionalidade da obra musical nós já a trazemos conosco desde o momento em que ela integra o nosso universo existencial, a nossa existência concreta. Como diz Heidegger, há uma co-originariedade entre ser e mundo, onde intuição e conceito, sensibilidade e categorias (para Heidegger, o pensamento categorial é o pensamento propositivo, que formula a proposição. V. Ernildo Stein, Racionalidade e Existência, Porto Alegre, Movimento, Porto Alegre, L\&PM, 1988, p.35s) estão juntos, inseparáveis, sem abismo. O que a nova hermenêutica sustenta de essencial é que não é só a técnica que ajuda a compreender a obra de arte. Invocamos ainda E. Stein (id. ib. p.38-9), sintetizando a necessidade de superação de uma visão exclusivamente epistemológica e lógica, e por uma fenomenologia da facticidade.

Mas qual tipo de análise, dentre as disponíveis, se configura como a mais propícia para acolher ou assimilar as considerações que fizemos emergir aqui? Ainda uma vez citamos textualmente Vattimo na sua Etica dell' Interpretazione (p.45):

"Em definitivo, não se trata de substituir uma 'descrição' hermenêutica da experiência a uma 'realística' ou objetivística... Uma filosofia hermenêutica não pode confundir-se com uma enésima 'descrição' das estruturas da experiência. Sustentando que a verdade não é acima de tudo a pro- 
posição que descreve fielmente, do exterior, um estado de coisas; mas que é evento, resposta a mensagens que provém de uma tradição, interpretação dessas mensagens e ocorrência de uma nova mensagem transmitida a outros interlocutores - a hermenêuticanão pode deixar de empenhar-se concretamente na resposta à própria tradição e no diálogo com as 'outras' tradições com as quais se acha em contato. A hermenêuticanão pode ser só teoria do diálogo... mas deve articular-se, se quiser ser coerente, como diálogo - portanto, empenhando-se concretamente nos confrontos dos conteúdos da tradição".

E dando sequência à argumentação, Vattimo (p.46) considera que não basta apenas uma "teoria do diálogo", ou uma mera descrição da experiência como continuidade como apelo e apego à riqueza estratificada da tradição. $\mathrm{O}$ diálogo, então, não pode restringir-se a loas ao diálogo... Para ele não é exclusivamente Gadamer que pode nos descortinar um panorama amplo nesse sentido, mas Heidegger, com a sua concepção de metafísica como história do ser e, pois, como unidade das "duas culturas", científica e humanística, e que não permanecendo, como o primeiro, apenas no âmbito da crítica da redução da verdade ao método científicopositivo; permitiria ao pensamento hermenêutico erigir um programa emancipativo mais radical.

Para Heidegger, segundo Vattimo, na história do ser, reconhecer a verdade da arte e da história além da verdade científica é apenas um momento de um processo muito mais amplo da tendência do ser em velar-se enquanto se desvela, ou seja, de acontecer como metafisica até que esta, ao culminar no Ge-Stell, a organização universal tecno-científica do mundo, chega ao fim e é ultrapassada. É nos confrontos desta história que não é a mera pertença ou dialogicidade, que a hermenêutica se instaura em termos radicalmente não-transcendentais, e passa a ser concebida não como a descoberta da estrutura dialógico-finita de toda experiência humana, mas em momento da história da metafisica, como história do 
ser, como etapa decisiva em que o ser se subtrai, reduz-se, dissolve-se, ao domínio das categorias metafísicas da presença estendida (desdobrada) numa posição não-contemplativa, oferecendo critérios e guias para operar escolhas de conteúdo.

Consoante tais premissas, relativiza-se o acolhimento a qualquer uma dentre as tendências analíticas disponiveis, já que se recomenda que o próprio comportamento analítico se configure de forma a não pretender constituir, nem isolada nem integradamente com outras tendências analíticas, nenhuma abordagem auto-suficiente com pretensões a explicar exaustivamente a obra musical. Relativiza-se, também, e fundamentalmente, a própria pretensão da análise, de obter respostas que não sejam meramente tecnocientíficas e que transponham a barreira do sentido e do conteúdo essencial e profundo da obra musical.

Finalizamos evocando o que poderia constituir a continuidade destas reflexões, que não cabe formular aqui por questões de tempo e de ocasião. Refiro-me a certas considerações de Heidegger sobre a Origem da Obra de Arte (Lisboa, Ed.70, 1990, p. 42-3): "O homem é impotente para dominar uma larga parte do que há no ser. Só pouco é conhecido. O conhecido permanece algo de aproximado; o dominado, algo de incerto. Nunca o ente está debaixo do nosso poder ou até na nossa representação (...) O ente só pode ser oculto no espaçode jogo do clareado. Todo o ente que vem ao nosso encontro e que nos acompanha, mantém esta estranha oposição da presença, na medida em que ao mesmo tempo se retém sempre numa ocultação. A clareira em que este ente assoma é em si, simultaneamente ocultação (...) A desocultação do ente nunca é um estado que está aí, mas sempre um acontecimento. A desocultação (verdade) não é nem uma qualidade das coisas no sentido do ente nem qualidade das proposições (...) A verdade acontece como o combate original entre clareira e ocultação. Um dos modos como a verdade acontece é o ser-obra da obra. Ao instituir um mundo e ao produzir a terra, a obra é o travar desse combate no qual se disputa a desocultação do ente na sua totalidade, a verdade (...) Mas no combate essencial, os combatentes elevam-se um 
ao outro à auto-afirmação das suas essências, cada um leva o outro para além de si-próprio" (p. 39). "Ser obra quer dizer instalar um mundo" (p. 35). Como destaca Vattimo em A sociedade transparente (p. 73), "o que importa mais a Heidegger não é a definição positiva do mundo que a poesia (a arte) abre e funda, mas sim a individuação do alcance de ruptura que a poesia (a arte) sempre, inseparavelmente, tem. Fundação e ruptura são o sentido dos dois aspectos que Heidegger indica como constitutivos da obra de arte, ou seja, a exposição do mundo e a produção da terra. $\mathrm{O}$ mundo exposto da obra é o sistema de significados que ela inaugura". 0 texto heideggeriano é rico para uma reflexão sobre a essência da representação, da cognitividade, apreensão, compreensão e explicação da obra musical.

Regis Duprat é musicólogo e Professor Titular no Instituto de Artes da UNESP-SP. 